\section{origmit cominumications.}

\section{ON THE RELATIVE MERITS OF THE DIF- FERENT ME'THODS OF TREATING FRACTURES OF THE LIMBS.}

\section{By JOSEPH SAMPSON GAMGEE.}

ce Prgan there is no subject more interesting to the practical surgeon than this of fracture of the limbs. . . . This is one of those subjects which has fallen into almost inextricable confusion; none, I believe, requires more to be historically explained. .... It is, I fear, but too certain, that while more has been written on the subject of fractures than on hernia, lithotomy, amputation or trepan, yet no two books correspond, no two authors agree, cren on the general points of practice; and every surgeon, whether in the army or in the navy, in a village or in a city, sets a broken limb as he writes his name, after a fashion of his own."*

With the forty years which have elapsed since John Bell nttered these remarks, they have gained rather than lost in justice. His own effort to reconcile the differences he so pointedly set forth, only added one to the list. Very little, if any better lot has befallen the essayists who have succeeded him, in endeavouring to establish, on a sound basis, this department of practical surgery. At this moment eren, the question of immediate reduction is pending; its solution in the negative being supported by Mr. South. + With all deference to this eminent authority, I must consider the experience of the vast majority as supporting the illustrious surgeon of St. Bartholomew's, in the assertion that " it is demonstrably truc that a broken limb cannot be too soon put to rights." $\neq$ The propriety of early reduction and accurate coaptation settled, the question arises, by what means is this to be maintained-displacement of the fragments and deformity to be prevented ? This is the desideratum, to attain which so many prificiples have been propounded, so many modes of practice continue in rogue ; this is the question to which our attention must be directed.

When we reflect that the treatment of fractures has been the farourite theme of most great surgeons; that each has adduced experience in support of his particular tenets; wo almost lose hope of solving the dispute on the basis of facts, which prinza facie is the only legitimate solution in a subject so purely experimental. But the whole history of medicine teaches us not to attach too much value to precepts, merely because facts are adduced in their support, "Quant aux faits prenez garde! Rien de plus décevant, de plus fallacieux, de plus perfide que le fait médical." Such Is the exclamation of Amédé Latour; $\S$ a severely cutting sarcasm I admit; but that it is unhappily true, as facts have for the most part been observed and related, no one can deny. The validity of facts has to be examined before conclusions professedly based upon them are assented to. Sach is the course I have elected to pursue on the present occasion.

As we trace back to their origin the different methods of treating fractures, we are struck by the fact that they have multiplied with time, and that advance in this branch of surgery has been marked with a divergence from unanimity of opinion, which is generally held to be the representative of perfect knowledge. It is so, indeed, when it is the expression of a judgment arrived at after free discussion of particulars, impartial, .comprehensive, philosophical generalisation. Such was not its cause in the present instance, but a servile veneration for authority, and a consequent enslaving of independent thought.

- John Bell's Principles of 8urgery, rol. 1, pp. 490-91. Iondon : 1815.

+ Tranalation of Chelius, vol. i, p 507 .

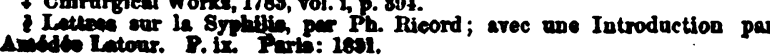

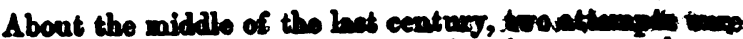
made to solve the then peading queetions in murgens the cone by the Acadómie Royale de Chirurgie, who propoeed a series of essays on such questions, to competition for prices; the other by Samuel Sharpe, whose Critical Inquiry into the Present Slate of Surgery was given to the world in 1750 . But in the five quarto volumes containing the Recueil des. Prix of the former, no question relating to the treatment of fractures is eren mooted; and the author of the latter work sets forth with the announcement (preface, op. cit.) that having only considered either such doctrines as, though generally received, were in his opinion ill-grounded, or such improvements as were yet but little known, he had not made any observations on the treatment of luxations and fractures, in the conviction that all eminent surgeons were agreed on the method of treating them.

True it is that, in the writings of Wiseman, Belloste, Moscati, Cheselden, and William Sharpe, instances are met with of slight deviation from the practice of the school of Cos, which for so many centuries had only suffered the slight and practically immatcrial modification of Galen and of Celsus; but the sergeant-chirurgeon of Charles I distinctly recommends, in his Chirurgicall Treatises (London: 1676. Book vii, p. 467), the method of Hippocrates for the "keeping the parts of a fracture joined together, and to defend them from inflammation". It was not until the year 1768 that a bold attempt was made by Percivall Pott to throw off the shackles of routine, in the Ten General Remarks on Fractures and Dislocations, which gave evidence of more power of independent thinking and sound judgment, than is perhaps to be found in any other essay of similar dimensions in the whole range of practical surgery. So important are the "general remarks" in question, for their intrinsic merits, and for the influence which they $\mathrm{cx}$ ercised on the practice of surgery, that I do not apologise for quoting from them such portions as contain Mr. Pott's particular views. "Neither extension nor counter-extension", he observes (Works, vol. i, p. 385), "can be necessary on account of the mere fracture, considered abstractedly. The broken ends of the bone or bones are of themselves inactive, and, if not acted upon by other parts, they would always remain motionless. When any attempt is made to put them into motion, they of themselves can make no possible resistance; nor can any be made on their part, save an accidental one, arising from the points of the fracture being entangled with each other; and when they have been once, by the hand of the surgeon, placed properly and erenly with regard to each other, they would for ever remain so. What then is the reason why fractured bones always suffer a greater or a.less degree of displacement? Why is a. broken limb almost always shorter than its fellow? What creates the resistance which we always find in attempting to bring the fractured parts aptly together? Whence does it proceed that, when we have done all that is in our power (according to this mode of acting), the ends of the fracture will, in many cases, become again displaced, and lameness and deformity frequently ensue? In short, what are the parts or powers which act on the bones, and which, by so acting on them, produce all these consequences? These parts are the muscles, the only moving powers in an animal body." He goes on to say (p. 388), that the putting the muscles in a state of tension is the cause of the resistance in setting a fracture, and that this resistance is best remored "by putting a limb in such position as shall relax the whole set of muscles belonging to or in connexion with the broken bone.". . "What is the posture", he inquires (p. 391, op. cit.), which almost every person, whose os femoris has been newly broken, puts himself into, in order to obtain ease, until he gets proper assistance? Do such people stretch out their limb, and place their leg and thigh straight, and resting on the calf and heel? I believe, seldom or never. On the contrary, do not such people almost always bend their knee, and lay the broken thigh on its outer side? and is not the reason why this must be the most easy posture obvious?" In accordance with this reaconing, If. Pust divected that petient with fencture of the 
Ning and leg should lis on the injured side, with the then bent on the abdomen, and the leg on the thigh. It is ver impartant to noto $\rightarrow$ fact too often orerlooked-that balled to his aid splints, which he tied loosely, it is true. but which he rendered much more efficient by having of weh length as to include both the joint above and the one below the seat of fracture, very justly inveighing against splints which do not fulfil this condition.

[To be continued.]

38, Stanhope Street, Loudon, November $18^{5}$

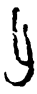

\section{METEOROLOGY OF CHOLERA.}

\section{By J. A. HINGFiston, Esq.}

No. $\mathbf{I}$.

Ix continuation of my last paper, I resume my account of the weather during the prevalence of cholera from Aug. 14th to October 28 th inclusive. The direction of the wind was almost invariably N.W., N., and N.E.S. Its relocity was very small; but so uniform was its direction, that, if the vane veered round to the S.W., it was but for a day or two, and then it returned to the N.W. or N.E.S. directly afterwards. A double current of air frequently mored in contrary directions, particularly on the 23rd and 24th of August; the uppermost being S.W. by W., and the lowermost N.W. by N. The S.E. winds have prevailed along this part of the coast much more than usual; and it is a chilly, damp, and unhealthy wind. In the non-choleraic years, the S.W. winds prevailed, with a good deal of rain; and these are healthy.

I agree with Mr. Glaisher that the cirrus clouds have been rare this summer. Between the 14th of August and November 16th, I find, on referring to my diary, that I have noted cirri on not more than eight days, separately. The mackerel sky has been frequent at noon, accompanying the sun for three or four hours in his meridian height. Occasionally some black smoky-looking clouds hare floated up from the N.W., and gone out to sea, dark and lowering. Amber-coloured sunsets hare been frequent, such as forerun a heavy gale from the S.W.; which, however, has never arrived. The mornings, whose dawn I am fond of watching, have been highly picturesque, with gilded strati, and a tender light, beaming across the ocean, grey and motionless, as the daylight broke. If anything be sublime, the mornings of the late summer have been so. The temperature has been, as Mr. Glaisher reports, almost invariably above the average.

Out of the seventy. five days, between the 14th of August and 28th of October, rain fell on twenty-one, leaving fiftyfour without even a drop of moisture. But the dews were heavy. Rain fell plentifully on Oct. 6th, Sept. 14th, and Aug. 24th; and there were showers on several other days between the 13th and 20th of September, from the S.W. or 8.E. The quantity of rain fallen is much below the average. There was no hail throughout the whole of this period. There have been many lunar and solar halos; but upon the coast this phenomenon seldom indicates anything more than the rising of a sea-mist, which is very capricious.

Thunder and lightning have been rare. Sheet lightning was visible at times, and small electric cumuli came into sight, but dissolved as soon as they arose. About the 26th of October, heavy piles of clouds, with lightning and distant thunder, hovered upon the horizon, a long way out at sea; but nothing came near the land.

When the S.E. wind has been blowing a long time, with a cloudless sky, a small darkish cloudlet forms in the eye of the 8.W., and remains stationary there for some hours every day. This little cloud is the forerunner of a gale from the Atlantic. It is most likely the focus or axis of a gyration of wind at the point where the N.E. meets the ale from the 8.W., forming a condensed nucleus of rapour. it is the anme as the amall white cloud that presages the typhoon in the China seas; which is a cyclone of terrife force and magnitude, except that, judging from the difference of colour, the one in the Chine seas is pasitively, whip. this in ours is negatively, electric. This little clend $p \mathrm{p}-$ peared in the west throughout the second or fatal wieek of September, this year, predicting (to $\mathrm{my}$ mind, at least) the decline of the disease as soon as the wind should shift round to the S.W., which came to pass in the thind week of September, when it blew a half gale from S.W., and the disease began to diminish.

Though the atmospheric changes do not account for the fact of the cholera, set the co-existence of cholera with recognised meteorological phenomena is, to say the least of it, a most remarkable circumstance. Thus, in the thind week of September, when both the barometer was falling and the disease declining, the greater number of freah cases bear date on 21 st and 23rd of that month, on which days the mercury rose from $29 \cdot 840$ to $30 \cdot 123$. See Registrar-General's Return, selected cases, for the weeks ending 23rd and 30th respectively, and compare the dates with the Meteorological Tables at the end.

Throughout the last year, there have been many causes farourable to the derelopment of discase. A scanty harrest, bad wheat, a scarcity of vegetables, an unhealthy condition of fresh meat, a deficiency of water, owing to the want of rain, numbers of small black flies, mildew or fungi; add to all this, the dearness of provisions, and a relative deficiency of nutrition among those classes of the population, which need it the most, but have the ferrest means of procuring it. These causes must have operated in the production of the disease.

It was in the month of March last that I noticed the lateritious deposits; but it was not till this November that I had an opportunity of seeing them again. This appearance and disappearance of the lithates corresponds with the commencement and the departure of the disease. If $I$ am correct, this circumstance is a curious one. I think I have observed the skin to be colder, and the flesh more flabby, than usual. There has been an absence of phlegmonous disease. Erysipelas, scarlatina, dehility, and a tendency to sloughing, characterise the autumnal illnesses. Perhaps the aspect of the population has been sickly, with a look of languor and dejection.

Brighton, Nor. 18th, 1854.

\section{CASE OF DIFFICLLT LABOUR FROM HYDROCEPHALCS.}

\section{By JAMES B. PROWSE, Esq.}

I HAVE read with much interest, in the Associatroy Jorkxal of October 13th (p. 921), a communication by Dr. J. G. Swayne of a "Case of Difficult Labour from Hydrocephalus" in a primipara, aged 20 . The case merits the attention of all interested in the practice of midwifery ; and I think it will be of some importance to give the particulars of the following case of labour.

The mother was a primipara, aged 38. When sent for on Monday, the 9th of September, I wis informed by the nurse that the membranes bad been ruptured; however, as there was very little uneasiness, I left. When I returned (the same day), there was no apparent progress except that (as was reported) the liquor amnii continued to be digcharged. The case went on in this way until the 13th at 3 A.M., when the symptoms and pains of more earnest labour were manifest. I then found, on examination, that although the os tincæ was not much dilated, the waters continued at intervals to escape.

The labour was a good one; for although slow in all its stages it was not protracter beyond twenty-seven hours after the commencement of the second stage; probably the first stage occupied a considerably longer period. The patient was delivered on September 14th, at 5 A.M., of a living child whose bead measured seven and a half inches 